\title{
Reliability and Factorial Validity of Non-Specific and Tennis-Specific Pre-Planned Agility Tests; Preliminary Analysis
}

\author{
by \\ Damir Sekulic ${ }^{1}$, Ognjen Uljevic ${ }^{1}$, Mia Peric ${ }^{1}$, Miodrag Spasic ${ }^{1}$, Miran Kondric ${ }^{2}$
}

Agility is an important quality in tennis, yet there is an evident lack of studies focussing on the applicability of tennis-specific agility performances and comparing them to equivalent non-specific agility performances. The aim of this study was to evaluate the reliability and factorial validity of three tests of pre-planned agility, performed in specific (with a tennis racquet) and non-specific (without a tennis racquet) conditions. The sample consisted of 33 tennis players (13 males and 20 females; age: $18.3 \pm 1.1$ years and $18.6 \pm 1.3$ years; body height: $185.4 \pm 51 \mathrm{~cm}$ and $169.3 \pm 4.2$ $\mathrm{cm}, 74.0 \pm 4.4 \mathrm{~kg}$ and $61.2 \pm 3.1 \mathrm{~kg}$, respectively). The variables comprised three agility tests: a 20-yard test, a T-test and the Illinois test, all performed in both specific and non-specific conditions. Between-subject and within-subject reliability were found to be high (Cronbach Alpha: 0.93 to 0.98; Coefficient of Variation: 3 to 8\%), with better withinsubject reliability and stability of the measurement for specific tests. Pearson's product moment correlations between the non-specific and specific agility performances were high $(r \geq 0.84)$, while factor analysis extracted only one significant latent dimension on the basis of the Guttman-Kaiser criterion. The results of the 20-yard test were better when the test was conducted in the specific conditions ( $t$-test $=2.66 ; p<0.05$ ). For the Illinois test, superior results were recorded in the non-specific conditions ( $t$-test $=2.96 ; p<0.05$ ), which can be explained by the test duration (about $20 \mathrm{~s}$ ) and non-specific locomotion forms such as rotational movements. Considering the findings of the present study, when testing tennis-specific pre-planned agility, we suggest using tests of short duration (less than 10 s) and sportspecific types of locomotion.

Key words: between-subject reliability, within-subject reliability, factor analysis, change of direction speed, applicability.

\section{Introduction}

Agility can be defined as an ability to quickly and efficiently change the direction and/or speed of movement (Sekulic et al., 2013). It is generally accepted that agility is an important quality in most sports where a quick and effective pre-planned or non-planned change of the direction is required (Sattler and Sajber, 2015; Sole et al., 2013). To clearly distinguish between capacity when an athlete: (i) has advanced knowledge of the necessary change of the direction (i.e. pre-planned agility); and (ii) has no such information, but must react to unpredictable (mostly visual) stimuli (i.e. non-planned agility), the terms change-of-direction-speed (CODS) and reactive agility are used (Sekulic et al., 2016).

Tennis is a sport in which both types of agility performances (i.e. CODS and reactiveagility) are important in specific circumstances

1 - University of Split, Faculty of Kinesiology, Croatia.

2 - University of Ljubljana, Faculty of Sport, Slovenia. 
(Cooke et al., 2011). Reactive agility is very important in game situations when players are positioned in the frontcourt and exchange shots from a relatively close distance. In these circumstances, players have to react quickly to the opponent's shots and efficiently change their position. Meanwhile, when both players are positioned in the backcourt and deep shots are exchanged, CODS is an important performance quality. In such a position, balls travel between players for a relatively long time, which allows proper positioning regardless of the perceptual and reactive capacities needed in reactive agility performance (Sekulic et al., 2014).

Previous studies have confirmed that different agility performances should not be observed as a unique quality (Sekulic et al., 2013). Namely, different agility performances are rarely found to be highly correlated, with this mainly depending on the type of movement involved in each agility performance (forward running, backward running, lateral displacement, rotational movements, non-stop running, stopand-go running, etc.), but also on the number of changes-of-direction included in a performance indicator (i.e. single change vs. multiple changes of direction) (Sekulic et al., 2013). It is particularly important that studies have rarely provided evidence of potential differences in agility performances with regard to the sport equipment used in a particular sport discipline.

Most specifically, in certain sports such as tennis, squash or rugby, agility is almost exclusively challenged when the athlete holds sport equipment (a racquet or a ball). The equipment directly influences the movement technique and results in a highly specific agility movement pattern. Although numerous studies have repeatedly observed agility as an important quality in tennis (Bloomfield et al., 2007; Fernandez-Fernandez et al., 2016; Murphy et al., 2015), only a few authors have directly specified use of a racquet during agility testing (BarberWestin et al., 2010; Filipcic et al., 2010). Furthermore, to the best of our knowledge, no studies have compared agility performances between tests executed with and without a racquet.

Therefore, the aim of this study was to evaluate the reliability and validity of several preplanned agility tests, performed with and without a racquet. We also evaluated the relationships between the observed tests in a sample of young tennis players. The increased knowledge in the field will allow more meaningful testing of agility in tennis and provide a basis for the conditioning process aimed at improving agility in this sport.

\section{Material and Methods}

\section{Participants}

The sample of participants consisted of 33 tennis players ( 13 males and 20 females; age: 18.3 \pm 1.1 years and $18.6 \pm 1.3$ years; body height: 185.4 $\pm 51 \mathrm{~cm}$ and $169.3 \pm 4.2 \mathrm{~cm}, 74.0 \pm 4.4 \mathrm{~kg}$ and $61.2 \pm$ $3.1 \mathrm{~kg}$, respectively). All of them were between 17 and 20 years of age and had practised tennis for more than 8 years. At the moment of testing, their regular training regime comprised $4-5 \mathrm{~h}$ of systematic training per day, with one day of rest per week. The majority of the training sessions were tennis-specific $(80-90 \%)$ with additional 10 $20 \%$ dedicated to strength and conditioning (i.e. strength training, plyometric, agility drills, endurance exercises, etc.). All participants were advanced tennis players and most participated in international-level tournaments, while four of them were members of national teams.

\section{Variables}

Apart from body height and body mass (measured by a Seca scale and a stadiometer; Seca, Birmingham, UK), the sample variables consisted of three agility tests: a 20-yard test, a T-test and the Illinois test, all performed with and without a tennis racquet. All tests were conducted on an outdoor, synthetic tennis court with athletes wearing their preferred sport shoes. At the time of testing, the outside temperature was $20-25^{\circ} \mathrm{C}$. To avoid diurnal variation, all athletes were evaluated within approximately the same time frame, from 8 to $10 \mathrm{am}$. All tests were performed in their standard form and while holding a tennis racquet. For all tests, three trials were performed with 3-5 min rest periods between the trials and tests. Tests were assigned randomly to each participant and approximately one-half of the participants performed non-specific tests (20YARD, ILLINOIS and T-TEST) and then tennis-specific tests while holding a racquet (R_20YARD, R_T-TEST, R_ILLINOIS), while the other half performed the tests in the opposite order. During all tests, a Brower electronic timing gate system (Brower Timing System, Salt Lake 
City, UT, USA) was used and timing gates were positioned at a height of $0.75 \mathrm{~m}$ and width of $3 \mathrm{~m}$. The time was measured with precision of $0.01 \mathrm{~s}$. A warm-up was conducted before the testing and included $10 \mathrm{~min}$ of light jogging, mobility exercises and dynamic stretching. Prior to the tests, participants performed several familiarisation trials at a slower tempo.

In the 20-yard test (Figure 1a), the participant started with a three-point stance from point $A$ and ran 5 yards to point $B, 10$ yards in the opposite direction to point $\mathrm{C}$, and then sprinted back 5 yards to point $A$. This exercise tests lateral change-of-direction-speed which is very common in tennis. The timing began on a sound signal and stopped when the subject had passed through the timing gate on their return.

For the T-test (Figure 1b), four cones were arranged in a T-shape, with cone B placed $9.14 \mathrm{~m}$ from cone $\mathrm{A}$, and two additional cones (C and D) placed $4.57 \mathrm{~m}$ on either side of cone $\mathrm{B}$. The subjects were asked to sprint forwards from A to $\mathrm{B}$, shuffle $4.57 \mathrm{~m}$ to the left to cone $\mathrm{C}$, shuffle 9.14 $\mathrm{m}$ to the right to cone $\mathrm{D}$, and shuffle $4.57 \mathrm{~m}$ back left to cone B before finally run backwards to cone A. The timing began on a sound signal and stopped when the subject had passed through the timing gate on their return.

The Illinois test is presented in Figure 1c. The length of the course (distance between $\mathrm{A}$ and B) was $10 \mathrm{~m}$ and the width (distance between $\mathrm{A}$ and $G$ ) was $5 \mathrm{~m}$. The test consisted of sprinting between $A$ and $B$, sprinting from $B$ to $C$, slalom running in between $\mathrm{C}-\mathrm{D}-\mathrm{E}-\mathrm{F}$, then again slalom running in the opposite direction (F-E-D-C), sprinting between $C$ and $G$, and final sprinting between $G$ and $H$. The cones were used to mark all points (A to $H$ ). Cones C-D-E-F were spaced $3.3 \mathrm{~m}$ apart. Participants started from a standing position.

\section{Statistical analyses}

After assessing the normality (KolmogorovSmirnov test), the means and standard deviations were reported for all variables. For all agility tests, the reliability was checked using coefficients of variations (CVs), Cronbach's alpha (CA) and Intra-item correlations (IIRs) (Hopkins, 2000; Sattler et al., 2012). The CA and IIR were calculated to determine the between-subject reliability, while the CVs were calculated to establish the within-subject reliability of testing.
An ANOVA for repeated measures and a Tukey post hoc test were used to detect any systematic bias between the individual trials of each test (Hopkins, 2000; Sattler et al., 2012).

To establish the factorial validity of the agility tests, factor analysis with a Guttman-Kaiser criterion of extraction was employed. In addition, the relationships between the tests were determined by Pearson's correlation coefficients (Sattler et al., 2012; Uljevic et al., 2013).

The differences between agility performances in the non-specific and tennisspecific tests were evaluated by a Student's t-test for dependent samples.

The statistical significance of $p<0.05$ was applied. Statistica ver 12.0 (Statosft, Tulsa OK) was used for all analyses.

\section{Results}

Between-subject reliability of the tests as evidenced by Cronbach alpha and IIR ranged from 0.93 to 0.98 and from 0.83 to 0.95 , respectively. The highest between-subject reliability was found for the T-TEST and R_ILLINOIS (IIR of 0.95 and 0.95, Cronbach alpha of 0.98 and 0.98 , for T-TEST and R_ILLINOIS, respectively). The within-subject reliability as shown by the $\mathrm{CV}$ was generally found to be higher for those agility tests performed while holding a tennis racquet ( $\mathrm{CV}$ of $3-4 \%$ ) than when performed in standard conditions, namely without a racquet (CV of 5-8\%) (Table 1).

When ANOVA was calculated between testing trials, a significant bias was found for all three agility tests performed without a tennis racquet. Post hoc analysis indicated significant differences between the first and second trials for all tests performed in non-specific conditions, with no significant differences between the second and third testing trials. The ANOVA showed no significant difference between testing trials for tests performed in tennis-specific conditions (with a racquet).

The correlations between the non-specific and tennis-specific agility performances were high $(\mathrm{r} \geq 0.84)$ and statistically significant $(p<$ $0.05)$. The strongest relationship was found between two performances of the T-test $(r=0.97 ; p$ $<0.05$ ), while a lower correlation was observed between the tennis-specific and non-specific Illinois agility tests $(\mathrm{r}=0.84 ; p<0.05)$ (Table 2$)$. 
The factor analysis calculated for all six tests extracted one significant latent dimension factor, with all tests highly projected on the extracted principal component. The latent dimension explained $88 \%$ of the tests' common variance (Table 3).

Players achieved significantly better results in the $\mathrm{R} \_20 \mathrm{YARD}$ than in 20YARD ( $\mathrm{t}$-value $=2.66 ; p$
$<0.05)$. At the same time, the performance in the ILLINOIS was superior when athletes performed the test in non-specific conditions (without a tennis racquet; $\mathrm{t}$-value $=-2.96 ; p<0.05)$. No significant difference was found for the T-TEST and R_T-TEST (Table 4).

Table 1

Reliability analyses of agility tests (CA - Cronbach Alpha, IIR - inter-item correlation, $\mathrm{CV}$-coefficient of variation)

\begin{tabular}{|c|c|c|c|c|c|}
\hline & Mean & $\mathrm{SD}$ & $\mathrm{CA}$ & IIR & $\mathrm{CV}$ \\
\hline 20YARD (s) & 5.54 & 0.34 & 0.93 & 0.83 & 0.05 \\
\hline 20YARD trial1 & 5.75 & 0.41 & & & \\
\hline 20YARDtrial2 & 5.56 & 0.39 & & & \\
\hline 20YARD trial3 & 5.51 & 0.45 & & & \\
\hline T-TEST (s) & 11.95 & 1.10 & 0.98 & 0.95 & 0.06 \\
\hline T-TEST trial1 & 12.29 & 1.01 & & & \\
\hline T-TEST trial2 & 12.01 & 0.99 & & & \\
\hline T-TEST trial3 & 11.94 & 1.10 & & & \\
\hline ILLINOIS (s) & 19.38 & 1.42 & 0.95 & 0.88 & 0.08 \\
\hline ILLINOIStrial1 & 19.49 & 1.39 & & & \\
\hline ILLINOIStrial2 & 19.43 & 1.35 & & & \\
\hline ILLINOIStrial3 & 19.43 & 1.60 & & & \\
\hline R_20YARD (s) & 5.40 & 0.38 & 0.95 & 0.89 & 0.03 \\
\hline R_20YARDtrial1 & 5.63 & 0.39 & & & \\
\hline R_20YARD trial2 & 5.57 & 0.42 & & & \\
\hline R_20YARD trial3 & 5.55 & 0.35 & & & \\
\hline R_T-TEST (s) & 11.85 & 1.01 & 0.98 & 0.93 & 0.04 \\
\hline R_T-TEST trial1 & 12.17 & 1.12 & & & \\
\hline R_T-TEST trial2 & 12.13 & 1.15 & & & \\
\hline R_T-TEST trial3 & 12.14 & 1.13 & & & \\
\hline R_ILLINOIS (s) & 19.55 & 1.30 & 0.98 & 0.95 & 0.04 \\
\hline R_ILLINOIStrial1 & 19.80 & 1.52 & & & \\
\hline R_ILLINOIStrial2 & 19.69 & 1.56 & & & \\
\hline R_ILLINOIStrial3 & 19.46 & 1.43 & & & \\
\hline
\end{tabular}

20YARD - 20-yard agility test; T-TEST - agility test over a t-shaped course;

ILLINOIS - Illinois agility test; $R_{-}$- indicates agility testing performed in tennisspecific conditions (athletes held a tennis racquet while performing the test) 
Table 2

Pearson's correlation coefficients between the standard and tennis-specific agility tests ( ${ }^{*}$ denotes significant correlations at $p<0.05$ )

\begin{tabular}{lccc}
\hline & R_20YARD & R_T-TEST & R_ILLINOIS \\
\cline { 2 - 4 } 20YARD & $0.91^{*}$ & $0.85^{*}$ & $0.88^{*}$ \\
T-TEST & $0.91^{*}$ & $0.97^{*}$ & $0.94^{*}$ \\
ILLINOIS & $0.84^{*}$ & $0.85^{*}$ & $0.95^{*}$ \\
\hline
\end{tabular}

20YARD - 20-yard agility test; T-TEST-agility test over a t-shaped course;

ILLINOIS - Illinois agility test; $R_{-}$- indicates agility testing performed in tennisspecific conditions (athletes held a tennis racquet while performing the test)

Table 3

Factor analysis of the standard and tennis-specific agility tests

\begin{tabular}{lc} 
& Factor \\
\cline { 2 - 2 } 20YARD & -0.92 \\
T-TEST & -0.98 \\
ILLINOIS & -0.93 \\
R_20YARD & -0.93 \\
R_T-TEST & -0.97 \\
R_ILLINOIS & -0.96 \\
Expl.Var & 7.03 \\
Prp.Totl & 0.88 \\
\hline
\end{tabular}

20YARD - 20-yard agility test; T-TEST-agility test over a t-shaped course; ILLINOIS - Illinois agility test; $R_{-}$- indicates agility testing performed in tennisspecific conditions (athletes held a tennis racquet while performing the test); Expl

Var-explained variance; Prp.Totl-proportion of total variance explained; $F$ correlations of the tests with the main component of factor analysis

Table 4

T-test differences between the tennis-specific and non-specific agility performances

\begin{tabular}{|c|c|c|c|c|c|c|}
\hline & \multicolumn{2}{|c|}{$\begin{array}{c}\text { Non-specific } \\
\text { (without a } \\
\text { racquet) }\end{array}$} & \multicolumn{2}{|c|}{$\begin{array}{l}\text { Tennis-specific } \\
\text { (with a racquet) }\end{array}$} & \multicolumn{2}{|c|}{$\begin{array}{c}\text { Student's t-test } \\
\text { for dependent samples }\end{array}$} \\
\hline & Mean & SD & Mean & $\mathrm{SD}$ & $\mathrm{t}$-value & $p$ \\
\hline 20YARD (s) & 5.54 & 0.38 & 5.40 & 0.34 & 2.66 & 0.01 \\
\hline T-TEST (s) & 11.95 & 1.01 & 11.85 & 1.10 & 1.00 & 0.21 \\
\hline ILLINOIS (s) & 19.38 & 1.30 & 19.55 & 1.42 & -2.96 & 0.01 \\
\hline
\end{tabular}

20YARD - 20-yard agility test; T-TEST - agility test over a -shaped course; ILLINOIS - Illinois agility test 


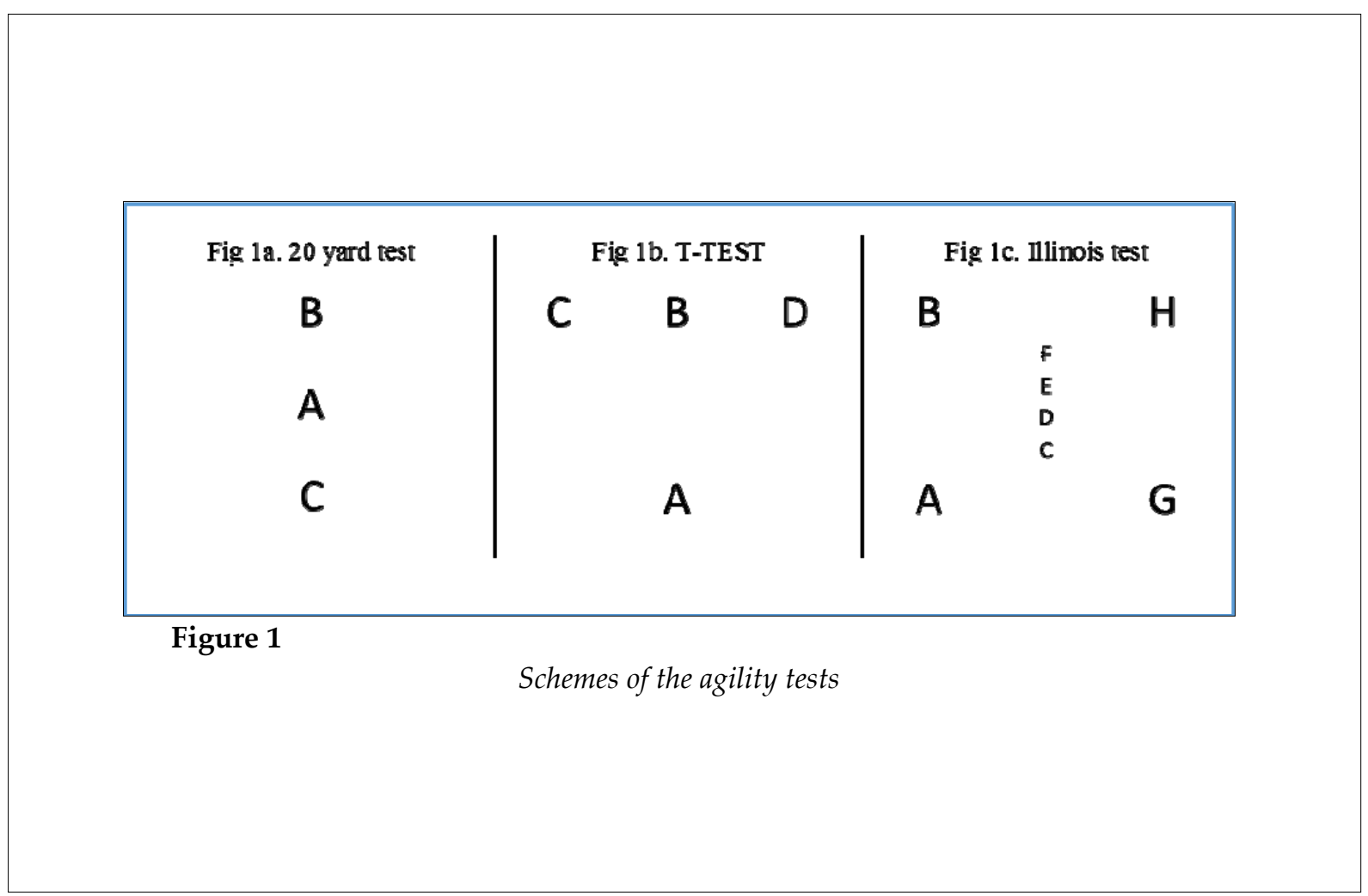

\section{Discussion}

There are several important findings of this study. First, the reliability of the applied tennisspecific and non-specific agility tests was high. However, the non-specific agility tests showed somewhat lower stability over the testing trials and lower within-subject reliability than the tennis-specific agility tests. Correlations between all tests indicated the applied tests should be considered as a unique quality, which was further confirmed by factor analysis. Finally, the young tennis players' performance in the agility tests of short duration was better when the test was performed in tennis-specific conditions (i.e. while holding a racquet during the test). Meanwhile, for the agility tests of longer duration, a superior performance was observed in non-specific conditions (without a racquet).

Reliability of the applied tests

In general, reliability is the main prerequisite of test applicability as it indicates the testing error (Bellar et al., 2015; Uljevic et al., 2013; Waldron et al., 2014). It is widely accepted that both within-subject and between-subject reliability are important indicators of the overall test quality (Idrizovic et al., 2015). In short, systematic changes between testing trials (i.e. a systematic decrease in performance due to fatigue or a systematic increase due to learning effects) may not necessarily alter the between-subject reliability (i.e. the subject actually retains their relative achievement compared to other test subjects). Meanwhile, in such circumstances, the within-subject reliability (i.e. relative changes in performance for each subject) might be questionable (Hopkins, 2000; Shrout and Fleiss, 1979; Weir, 2005). Considering that in our study both within- and between-subject reliability were found to be appropriate, we may highlight a low measurement error of the tests applied in evaluating agility among advanced-level young tennis players.

Both types of agility tests evaluated herein (i.e. those executed while holding a tennis racquet and those performed without a racquet) have similar between-subject reliability, as indicated by the values of Cronbach Alpha and IIR. However, it is clear that the tennis-specific agility tests have better within-subject reliability (as indicated by $\mathrm{CV}$ ). A more detailed overview of the descriptive statistics of each single testing trial and a comparison of the testing trials for each test allow a meaningful analysis of such findings. Namely, 
differences between the trials show evidently smaller changes between trials for the tennisspecific tests. For example, differences between trials for the R_20YARD were 1\% (between trial 1 and trial 2), $1.4 \%$ (between trial 1 and trial 3) and less than $0.5 \%$ (between trial 2 and trial 3). At the same time, between-trial differences for the 20YARD were 3,4 and $1 \%$, respectively. Evidently, the participants varied in performance when tested in the non-specific agility tests and altogether, this resulted in stronger within-subject reliability for the specific-agility performances.

Our results pointing to the somewhat better reliability of the tennis-specific tests of agility are consistent with previous studies that examined the problem of sport-specific tests in other sports. For example, Sisic et al. (2016) recently reported better reliability of basketball-specific tests of preplanned agility compared to more general testing procedures in basketball juniors. Similar results were reported by Sattler et al. (2012) who investigated sport-specific and non-specific jumping tests in volleyball, and Peric et al. (2012) who compared the reliability of jumping tests performed on the ground and in the water in a sample of synchronised swimmers. It is interesting to note that the tennis-specific agility tests had better reliability than the standard (nonspecific) agility tests, although the tennis-specific tests were more complex or, at least, more difficult than the standard ones. While performing the tennis-specific tests, the subjects had to run and perform directional changes with a $70 \mathrm{~cm}$ long racquet that weighs $300-350 \mathrm{~g}$.

\section{Validity of the applied tests}

All tests observed herein were found to be highly correlated. Furthermore, factor analysis identified all tests as being significantly projected on a single latent dimension (factor analysis component). As a result, all the agility tests used in this study should be considered as a measure of single capacity, pre-planned agility. These results actually conflict somewhat with previous studies that observed athletes from different sports and frequently reported relatively low correlations between various agility performances. In those studies, authors observed varying agility performances with regard to different movement patterns in a range of agility tests (rotational movement, zig-zag movement, forward-backward running, lateral displacement, stop-and-go, non- stop, etc.), identified relatively independent dimensions and interpreted independent agility performances (Metikos et al., 2003; Sekulic et al., 2013). However, the main explanation of the differences between our findings and those reported previously should be found in the sample of tested subjects. In short, the samples in previous studies included athletes from different sports (basketball, soccer, handball, tennis), while we solely examined tennis players (Metikos et al., 2003; Sekulic et al., 2013).

Most specifically, it is reasonable to expect that different sports develop sport-specific agility such as forward-backward running in basketball, zig-zag sprinting agility in soccer, etc., as indirectly confirmed in recent investigations where authors developed sport-specific agility tests for handball, emphasising the crucial movement agility in this sport (i.e. lateral displacement) (Spasic et al., 2015). Therefore, in those studies including athletes from different sports, a relatively low correlation between different agility tests is actually a natural consequence of the development of some sportspecific type of agility (Metikos et al., 2003; Sekulic et al., 2013). For example, soccer players achieved excellent results in zig-zag agility, which is common in their sport, while basketball players showed superior results in agility that included forward-backward running and lateral displacement (i.e. T-TEST) (Metikos et al., 2003; Sekulic et al., 2016). This naturally resulted in relatively low correlations between different agility tests and led to the different agility performances being identified as independent qualities. Unlike the aforementioned studies, we only observed tennis players. During their involvement in tennis, they had all developed sport-specific agility. Therefore, a superior agility performance in one test will almost certainly be related to a superior agility performance in other tests, despite possible differences in movement patterns between particular agility tests.

\section{Differences in performance between the specific and non-specific tests}

Although detecting differences between agility performances in specific and non-specific tests was not the main aim of this study, the results deserve special attention. In short, the subjects achieved better results in the 20-yard test when performing this test with (R_20YARD) 
compared to without a tennis racquet (20YARD). We should highlight that the 20-yard test includes two changes in direction performed after 5 (first-) and 10 yards (second- change of direction) of a maximal semi-lateral sprint. It could thus be hypothesised that holding a racquet in one's hand should negatively impact the performance, whereas the results we obtained actually pointed to the opposite conclusion. Although somewhat surprising, these results are also a natural consequence of long-term involvement in tennis.

Players included in this study had been involved in tennis for over 8 years. Throughout this period, they participated in thousands of hours of systematic training and tennis matches. In practically all circumstances and situations when they had to perform a quick change of direction, they actually did it while holding a racquet in their hand. As a result, an agility performance without a tennis racquet would be unnatural for them since they were unfamiliar with that type of agility performance. This was directly confirmed in the reliability analyses where we found better within-subject reliability (i.e. smaller between-trial differences in testing results) and a lower CV (i.e. better reliability) for the tennis-specific tests. As a result, superior performances in the R_20YARD compared to the 20YARD were a logical consequence of greater familiarity with the tennis-specific agility performance (which includes a racquet), regardless of the racquet's weight and length.

The contradictory findings of the Illinois tests, where the subjects achieved significantly better results in non-specific testing (i.e. without a racquet) are an outcome of: (i) longer test duration; and (ii) non-specificity of the movement patterns (i.e. locomotion forms) in this test. The Illinois test lasts about $20 \mathrm{~s}$, which is four times longer than the 20-yard test. The longer the test duration, the more apparent the burdening effect of the external load (i.e. the tennis racquet). With duration of $20 \mathrm{~s}$, execution of the Illinois test requires a significant contribution of the lactate metabolism (McArdle et al., 2006). Therefore, the racquet's negative influence is more apparent, which consequently alters the overall performance.

One could argue that performing for $20 \mathrm{~s}$ is not uncommon in tennis and, therefore, such test duration should not be considered problematic for tennis players. Indeed, while we can agree with such criticism, the problem of non-specific movement patterns and locomotion forms also deserves attention. The Illinois test comprises locomotion forms that can hardly be seen as standard for tennis. In brief, rotational locomotion actually does not exist in tennis and therefore, players are unfamiliar with it. While such movement is partly a natural locomotion form used in everyday life, at the same time it is completely unnatural if one has to perform it while holding a tennis racquet. Consequently, while a tennis racquet is a 'natural environment' in performance of the 20-yard test, even for tennis players it negatively impacts their performance in the Illinois test.

\section{Study limitations}

The main limitation of this study arises from the fact we only studied tests requiring nonreactive agility performances. While reactive agility performance is a crucial factor in overall tennis performance, this should be more precisely studied in the future. Furthermore, our study involved young tennis players and almost twice as many females as males, while the analyses were not gender stratified. Therefore, generalisability of the results is limited for such samples of subjects. However, given the limited number of studies investigating this problem in tennis and in other sports where agility is performed specifically (i.e. while holding equipment such as a racquet and/or a ball), we hope that our results, although not the final word on the problem, will contribute to knowledge in the field.

\section{Conclusion}

The tests we used were found to be reliable and applicable for defining pre-planned agility in young tennis players. We contend that agility performance in tennis should be evaluated by tests in which athletes carry out agility manoeuvres while holding a tennis racquet, as actually occurs in the sport.

In testing tennis-specific agility, we suggest using tests of short duration (less than $10 \mathrm{~s}$ ). Longer test duration will result in higher anaerobic-lactate metabolic demands, making the agility testing questionable. Namely, it is possible that advanced lactate endurance impacts testing results, which should be avoided if the aim is to 
test agility performance.

Different agility performances observed in this study were highly correlated. It led us to conclude that different types of movement patterns could be used in the agility testing of tennis players. According to our results, agility performance can be effectively evaluated regardless of the locomotion form included in the agility testing protocol. However, non-specific locomotion forms such as rotational movements should be avoided.

\section{References}

Barber-Westin SD, Hermeto AA, Noyes FR. A six-week neuromuscular training program for competitive junior tennis players. J Strength Cond Res, 2010; 24: 2372-2382. doi: 10.1519/JSC.0b013e3181e8a47f

Bellar D, Marcus L, Judge LW. Validation and Reliability of a Novel Test of Upper Body Isometric Strength. J Hum Kinet, 2015; 47: 189-195. doi: 10.1515/hukin-2015-0074

Bloomfield J, Polman R, O'Donoghue P, McNaughton L. Effective speed and agility conditioning methodology for random intermittent dynamic type sports. J Strength Cond Res, 2007; 21:1093-1100. doi: 10.1519/R-20015.1

Cooke K, Quinn A, Sibte N. Testing Speed and Agility in Elite Tennis Players. Strength Cond J, 2011; 33(4): 6972. doi: 10.1519/SSC.0b013e31820534be

Fernandez-Fernandez J, de Villarreal ES, Sanz-Rivas D, Moya M. The Effects of 8-Week Plyometric Training on Physical Performance in Young Tennis Players. Pediatr Exerc Sci, 2016; 28: 77-86. doi: 10.1123/pes.2015-0019

Filipcic A, Pisk L, Filipcic T. Relationship Between the Results of Selected Motor Tests and Competitive Successfulness in Tennis for Different Age Categories. Kinesiology, 2010; 42: 175-183

Hopkins WG. Measures of reliability in sports medicine and science. Sports Med, 2000; 30: 1-15

Idrizovic K, Uljevic O, Spasic M, Sekulic D, Kondric M. Sport specific fitness status in junior water polo players--Playing position approach. J Sports Med Phys Fitness, 2015; 55: 596-603

McArdle WD, Katch FI, Katch VL. Essentials of Exercise Physiology. Lippincott: Williams \& Wilkins; 2006

Metikos D, Markovic G, Prot F, Jukic I. Latent structure of agility obtained by a battery of tests. Kinesiology, 2003; 35: 14-29

Murphy AP, Duffield R, Kellett A, Gescheit D, Reid M. The Effect of Predeparture Training Loads on Posttour Physical Capacities in High-Performance Junior Tennis Players. Int J Sports Physiol Perform, 2015; 10: 986-993. doi: 10.1123/ijspp.2014-0374

Peric M, Zenic N, Mandic GF, Sekulic D, Sajber D. The reliability, validity and applicability of two sportspecific power tests in synchronized swimming. J Hum Kinet, 2012; 32: 135-145. doi: 10.2478/v10078012-0030-8

Sattler T, Sajber D. Change of Direction Speed and Reactive Agility Performance - The Reliability of a Newly Constructed Measuring Protocols: A Brief Report. Kinesiologia Slovenica, 2015; 21: 31-38

Sattler T, Sekulic D, Hadzic V, Uljevic O, Dervisevic E. Vertical jumping tests in volleyball: reliability, validity, and playing-position specifics. J Strength Cond Res, 2012; 26: 1532-1538. doi: 10.1519/JSC.0b013e318234e838

Sattler T, Sekulic D, Spasic M, Peric M, Krolo A, Uljevic O, Kondric M. Analysis of the Association Between Motor and Anthropometric Variables with Change of Direction Speed and Reactive Agility Performance. J Hum Kinet, 2015; 47: 137-145. doi: 10.1515/hukin-2015-0069

Sekulic D, Krolo A, Spasic M, Uljevic O, Peric M. The development of a new stop'n'go reactive-agility test. J Strength Cond Res, 2014; 28: 3306-3312. doi: 10.1519/JSC.0000000000000515 
Sekulic D, Pehar M, Krolo, A, Spasic M, Uljevic O, Calleja-Gonzalez J, Sattler T. Evaluation of basketballspecific agility; applicability of pre-planned and non-planned agility performances for differentiating playing positions and playing levels. J Strength Cond Res, 2016; e pub ahead of print

Sekulic D, Spasic M, Mirkov D, Cavar M, Sattler T. Gender-specific influences of balance, speed, and power on agility performance. J Strength Cond Res, 2013; 27: 802-811. doi: 10.1519/JSC.0b013e31825c2cb0

Shrout PE, Fleiss JL. Intraclass correlations: uses in assessing rater reliability. Psychological Bulletin, 1979; 86: 420

Sisic N, Jelicic M, Pehar M, Spasic M, Sekulic D. Agility performance in high-level junior basketball players; the predictive value of anthropometrics and power qualities. J Sports Med Phys Fitness, 2016; 56: 884893Sole CJ, Moir GL, Davis SE, Witmer CA. Mechanical analysis of the acute effects of a heavy resistance exercise warm-up on agility performance in court-sport athletes. J Hum Kinet, 2013; 39: 147156. doi: 10.2478/hukin-2013-0077

Spasic M, Krolo A, Zenic N, Delextrat A, Sekulic D. Reactive Agility Performance in Handball; Development and Evaluation of a Sport-Specific Measurement Protocol. J Sports Sci Med, 2015; 14: 501-506

Uljevic O, Spasic M, Sekulic D. Sport-specific motor fitness tests in water polo: reliability, validity and playing position differences. J Sports Sci Med, 2013; 12: 646-654

Waldron M, Worsfold P, Twist C, Lamb K. The reliability of tests for sport-specific skill amongst elite youth rugby league players. Eur J Sport Sci, 2014; 14: S471-477. doi: 10.1080/17461391.2012.714405

Weir JP. Quantifying test-retest reliability using the intraclass correlation coefficient and the SEM. J Strength Cond Res, 2005; 19: 231-240. doi: 10.1519/15184.1

\section{Corresponding author:}

\section{Damir Sekulic}

University of Split, Faculty of Kinesiology, Teslina 6, 21000 Split, Croatia

Phone: +385 21302440

E-mail: dado@kifst.hr 